TURNER, Mark. The origin of ideas: Blending, creativity, and the human spark. New York, NY: Oxford University Press, 2014. 300 p.

\title{
The Origin of Ideas: Blending, creativity, and the human spark
}

\author{
Marco Antônio de Oliveira*
}

Desde a década de 1980, principalmente a partir dos trabalhos sobre metáfora (Lakoff; Johnson, 1980; Lakoff; Turner, 1989) e espaços mentais (Fauconnier, 1985), a área da linguística cognitiva vem se estabelecendo como uma das áreas de pesquisa mais interessantes. E é exatamente aí que a teoria da integração conceitual (Blending Theory) vem se impondo, numa série de textos importantes (Turner, 1996; Fauconnier, 1997; Fauconnier; Turner, 1998, 2002; Turner; Fauconnier, 1995). O cerne da teoria da integração conceitual é bastante evidente. A ideia básica é a de que as representações linguísticas indicam que as pessoas formam conceitos através de uma integração constante de informações provenientes de domínios diferentes de conhecimento e experiências. É como se a combinação de elementos velhos conduzisse à criação de elementos novos. E é isso que fazemos na nossa maneira de pensar corriqueira. Assim, dois, ou mais, espaços de entrada (input spaces), cada um deles entendido como uma rede de elementos significativos, unidos por relações internas, irão fornecer, com base nas semelhanças entre eles, elementos para a construção de um espaço mais abstrato, o espaço genérico, que irá refletir aquilo que os espaços de entrada têm em comum e que pode ser juntado num espaço novo, integrado (blended space). No caso da integração de escopo duplo, que é o principal tipo de integração considerada no livro, o mapeamento de espaços envolve redes potencialmente conflitantes. Nesse novo livro, Turner retoma, conforme ele mesmo nos informa na p. vii, uma série de artigos e capítulos de livros publicados anteriormente, fornecendo-nos, assim, um texto que, de certa forma, refaz todo o percurso da teoria da integração conceitual, levantando questões que ainda precisam ser esclarecidas e abrindo novas perspectivas de pesquisa.

O livro tem, ao todo, 300 páginas, distribuídas em dez capítulos, um apêndice, notas, referências e um índice remissivo.

* Pontifícia Universidade Católica de Minas Gerais (PUC Minas). 
O primeiro capítulo (The human spark) nos apresenta o tema central da obra, a capacidade humana de criar ideias novas, que ultrapassam as situações locais imediatas. A pergunta que se coloca no início do livro é: o que é que somente os seres humanos são capazes de fazer? Segundo Turner o que nos diferencia das outras espécies é exatamente nossa capacidade de produzir ideias novas o tempo todo. E isso vem ocorrendo há pelo menos 50.000 anos. Essas ideias novas são capazes de influenciar outras mentes e de mudar o mundo. São elas que nos permitem ressignificar o mundo e os outros, conduzindo a novas ideias, de maneira recursiva. São elas que dão suporte à criatividade. Ideias novas não são instintos ou fruto deles, mas resultado de uma operação de integração de conceitos, ou blending. Assim sendo, somos nós, os seres humanos, a origem das ideias novas. Nós, e não outras espécies, nascemos com essa centelha que nos permite criar e entender novas ideias. Mas o que é essa operação de blending? Segundo Turner, trata-se da principal alavanca cognitiva da mente humana moderna. Na verdade, outras espécies são capazes de produzir integrações simples, mas o grande avanço evolucionário se deu quando o homem, e somente o homem, desenvolveu a capacidade para realizar um tipo de integração avançada, ou de escopo duplo, um tipo especial de blending que Turner apresenta no segundo capítulo. É importante dizer que as operações de blending se dão abaixo do nível de consciência, ou seja, o blending é tão natural para o ser humano que passa despercebido. Ainda no primeiro capítulo, o autor retoma as noções de espaço mental e de rede mental. Espaços mentais são pacotes, constructos ou cenários mentais, idealizados, que se estruturam a partir de diferentes frames. As redes mentais, por sua vez, são constituídas de espaços mentais conectados entre si, podendo apresentar vários tipos de conexões conceituais (identidade, espaço, tempo, entre outras) entre os espaços que as compõem. O que o autor nos mostra, ao longo do texto, é que podemos integrar (blend) espaços mentais numa rede mental de maneiras altamente criativas. A integração que daí resulta, por sua vez, é um novo espaço mental, caracterizado por um significado novo que daí emerge, e que pode servir de base para uma nova integração. Convém notar que os elementos e relações projetados numa integração de dois espaços mentais são sempre parciais e seletivos. Segundo Turner, uma das características do blending é a de colocar em escala humana porções de pensamento que, de outra forma, não poderíamos controlar. Uma rede mental não está necessariamente numa escala humana, mas o blending está e, desse modo, podemos pensar sobre a rede mental como um todo. Ou seja, o blending é uma pequena 
compressão encapsulada que nos permite lidar com o restante da rede mental. Enquanto compressão ela pode ser desencapsulada e expandida conforme as circunstâncias. As palavras iniciais de Turner, no capítulo 1, fornecem um panorama geral do tema do livro. É no capítulo 2 (Catch a fire), no entanto, que o autor refina a noção de blending. O capítulo 2 procura responder a duas questões: (a) o que é o blending? (b) como ele surge? De início o autor nos apresenta evidências arqueológicas que comprovam que a capacidade humana para o blending não é algo novo. Ao comentar a estatueta do Homen-leão, uma peça de marfim de cerca de 32.000 anos, o autor salienta a antiguidade de uma cultura humana criativa. Para Turner, o que essa estatueta nos mostra é uma habilidade mental para a combinação de dois conceitos diferentes, o de homem e o de leão, num terceiro conceito, o de homem-leão, que não é nem um homem nem um leão. Esse caso nos mostra que o blending é sempre uma inovação, uma ideia nova. Em outras palavras, o blending é a origem das novas ideias. Essa 'faísca humana', uma espécie de dom da nossa evolução, que permite ao ser humano a integração de conceitos, surgiu por volta de 50.000 anos atrás, no período do Paleolítico Superior. Nesse ponto, o homem foi capaz de produzir representações para conceitos, o que permitiu a invenção e a preservação da cultura. Desde então somos capazes de ter novas ideias o tempo todo. É importante observar que nossos cérebros são limitados e, assim sendo, fazemos a integração conceitual através de processos biológicos que são limitados ao aqui e agora. O pensamento e a memória, por exemplo, estão infalivelmente presos ao aqui e agora. Mas, se as coisas são assim, como é que somos capazes de lidar com ideias que ultrapassam o aqui e agora? Segundo Turner, isso é possível porque o blending nos permite acomodar a vastidão do mundo numa escala com a qual a mente humana possa lidar. É o blending que nos permite lidar com a vasta rede mental. Essa integração conceitual é pequena o suficiente para ser transportada mentalmente e, ao mesmo tempo, passível de ser expandida para se conectar a situações reais. Um exemplo interessante que Turner desenvolve é o da concepção do dia cíclico. Sabe-se que nenhum dia é igual ao dia precedente ou ao que virá depois dele. São todos diferentes e não se repetem. Essa sequência infinita de dias não caberia na nossa memória de trabalho, não seria manobrável nem mentalmente portável. Contudo, não temos nenhum problema com isso: fazemos uma integração conceitual dessa sequência infinita de dias na concepção do dia cíclico, ou seja, comprimimos as analogias, ou semelhanças, entre os vários dias na noção de DIA e, ao mesmo tempo, comprimimos as desanalogias, ou diferenças, na 
ideia das mudanças ocorridas no DIA. Em resumo, embora nenhum dia se repita, o dia cíclico (ou DIA) se repete. E é exatamente essa noção de dia cíclico que está numa escala humana, manobrável, podendo ser expandida a qualquer momento para atender a uma nova situação. Esse dinamismo entre a compressão e a expansão de ideias está sempre envolvido no pensamento humano. É aí que o ser humano leva vantagem sobre as outras espécies: somente nós temos a habilidade de ampliar o alcance de nosso pensamento de modo criativo, sistemático, duradouro, rápido e repetido. Fazemos isso o tempo todo. E é a isso que se chama de integração conceitual avançada (ou de escopo duplo). A integração conceitual avançada ocorre quando dois espaços mentais de input apresentam estruturas organizacionais básicas conflitantes, como no caso do Homem-leão, ou quando as relações entre elas manifestam alguma distinção básica que, mesmo assim, são mescladas de tal modo que a integração entre elas exibe apenas partes de cada uma delas, permitindo uma nova estrutura organizacional, como no caso do dia cíclico (que sempre começa com uma aurora e termina no crepúsculo, como qualquer dia).

Em seguida, Turner nos conduz, nos capítulos de 3 a 9, a uma série de comentários específicos sobre outros tipos de ideias e sua relação com a noção de blending. No capítulo 3 (The Idea of You) vemos como a integração conceitual avançada nos possibilita ter ideias sobre outros seres e sobre outras pessoas, sobre como lidar com elas e sobre como interagir com elas. Uma vez que não temos acesso direto à mente de outras pessoas, como sabemos quem elas são e como podemos entendê-las? O que fazemos é projetar a posse de uma mente, com base naquilo que conhecemos sobre nós. Fazemos a mesma coisa quando atribuímos uma mente a uma foca, um animal com muitas semelhanças anatômicas e de movimento com os humanos, semelhanças essas que sugerem atenção e intenção. Essa atribuição de uma mente a outras espécies e a outras pessoas é algo que fazemos constantemente. Essa ideia não é nova e, como Turner nos mostra, está presente nos trabalhos de Aristóteles, Hume e Darwin. O mesmo acontece nas mentes atribuídas a personagens de histórias infantis, nas quais animais são capazes de várias ações tipicamente humanas, como falar. É o caso do Pateta, do Pato Donald, do Mickey e do Scooby-Doo. O caso do Pato Donald é interessante, pois mostra como a projeção é realmente seletiva: a fala do Pato Donald não pode ser encontrada na fala natural de nenhum ser humano, nem podemos encontrar nenhum pato que fale. Mas o Pato Donald fala, e fala como um pato. No caso brasileiro, o Boto da Amazônia seria um bom exemplo de integração conceitual avançada: trata-se de um peixe 
que tem características e comportamentos humanos. Não é nem um peixe nem um homem; é o Boto das lendas amazônicas. Nesses casos, o que temos é uma realidade ficcional, que é criada numa rede mental e que só é real dentro dessa rede mental. Em resumo, acreditamos que, de fato, as pessoas possuem uma mente, embora não sejamos capazes de reconhecê-la. Nossa habilidade de conceber as pessoas como possuidoras de uma mente plena depende da integração conceitual avançada, na qual projetamos aquilo que conhecemos a partir de nossas próprias mentes. No caso da ficção, fazemos isso numa rede mental fictícia. Mas, se pensarmos bem, todas as mentes atribuídas, inclusive as das pessoas, são 'mentes fantasiadas', uma vez que essas últimas não são acessíveis. Até seres inanimados ou abstratos podem receber uma mente atribuída, como lugares e brinquedos que falam e agem. Turner sustenta esse ponto com uma citação de Adam Smith. Um exemplo mais próximo seria o da figura de Pinocchio. E isso se faz através da integração conceitual avançada, que se presta à ancoragem de redes mentais difusas, permitindo-nos manobrá- las em escala humana. De outra forma essas redes mentais seriam inadaptáveis à nossa maneira de pensar. Sua função é, basicamente, a de comprimir informações em algo que possamos reter na mente. No que se refere àquilo que projetamos de nós mesmos na integração conceitual avançada, Turner se pergunta se há alguma regulagem para isso. Podemos projetar o que quisermos ou há alguma limitação para isso? Sua resposta é clara: o que projetamos é limitado socioculturalmente. O capítulo 3 apresenta, ainda, como bonificação, uma discussão entre as ideias de Turner e as de Tomasello, ou seja, entre uma abordagem em termos de integração conceitual avançada e uma abordagem em termos de uma "teoria da mente". A discussão, nesse momento, é bastante interessante e cabe ao leitor formar sua própria opinião a respeito. As seções finais do capítulo 3 especificam um pouco mais as condições em que a integração conceitual avançada se dá: ela depende de outras capacidades mentais, como a memória, a atenção e a percepção; depende também de um enquadramento sociocultural; depende de tempo e espaço, o que pode ser pontual ou permanente.

No capítulo 4 (The Idea of I), Turner comenta uma série de conceitos, como os de 'ground', de atenção compartilhada, de mente compartilhada, concentrando-se nas maneiras pelas quais a integração conceitual nos permite ter ideias sobre nós mesmos. A questão parece trivial, mas não é. Afinal, como conseguimos manter uma mesma ideia sobre nós mesmos, sobre quem somos, quando o nosso self se estende no tempo e no espaço? Fato é que 
construímos uma identidade estável, mesmo sob as condições de mudança que inevitavelmente recaem sobre nós. É claro que nossa identidade pode incorporar nuances diferentes, a depender da rede mental que esteja ativa em nosso cérebro nas circunstâncias do momento. Independentemente disso, nosso self se mantém estável e constante, como algo que encampa as eventuais diferenças e mudanças. Turner nos diz que as culturas procuram garantir esse self estável e constante de várias maneiras. Uma delas é através do nome próprio. Um nome próprio $\mathrm{X}$ se refere a um mesmo self, desde seu nascimento até seu falecimento, não interessando as mudanças ocorridas ao longo do tempo. O ponto que Turner quer garantir aqui é: essa manutenção do self só é possível dentro de uma integração conceitual que comprima as analogias entre os vários estágios do self numa relação de identidade, relegando as desanalogias às mudanças ocorridas no self ao longo do tempo. Somente a integração conceitual nos permite dizer que se trata do mesmo self o tempo todo. É exatamente a possibilidade de integrar conceitualmente o self que nos ajuda a lidar com o enorme volume de material e informações disponíveis no restante da rede mental, material esse que recobre grandes porções de tempo, espaço e causa. Não fosse assim, não teríamos condições cognitivas de explorar e manobrar a vastidão dessa rede mental. Com relação às lembranças passadas, Turner nos diz que nós construímos um elemento que vai funcionar como um self prévio numa integração conceitual. E fazemos isso pela projeção de elementos de nosso self presente nessa integração conceitual. É assim que podemos garantir uma mente ao nosso self passado. E a razão para as coisas serem assim é simples: estamos biologicamente presos ao presente. Nenhum de nós tem como voltar ao passado. Até mesmo nossa memória é parte de nossa atividade biológica do presente. São nossas condições do presente que nos permitem 'sentir' as lembranças de um modo ou de outro. Resumindo, nosso self se situa em uma rede mental ampla, de modo distribuído por tempo, espaço, ponto de vista e foco, configurando-se de maneiras diferentes em situações diferentes. Ele é, na verdade, uma rede de 'selves'. Se nosso self passado se faz pela integração conceitual de nosso self presente + nossa memória das condições passadas, nosso self futuro se faz pela integração conceitual de nosso self presente + um conjunto de condições imaginadas. Nesse ponto do texto, Turner faz uma contraposição interessante entre a teoria da integração conceitual, por um lado, e a teoria dos jogos, em suas várias manifestações, por outro lado. O que o autor nos mostra é que a mente não funciona como uma estratégia do tipo 'game-playing' e não deve ser vista em seu funcionamento 
como uma sequência de procedimentos. A mente é criativa. Criamos não apenas o nosso self, mas também o self de outros. E na interação com outros imaginamos todos que estamos prestando atenção às mesmas coisas. Nossas mentes e nossa atenção são, assim, compartilhadas. É essa rede integrada em termos de atenção compartilhada que é indispensável para o conceito de comunicação humana e nos fornece o enquadramento mental conhecido como 'ground'. O 'ground' contém o falante, o ouvinte, o tempo e o espaço do evento de fala, sendo parte da interface que a consciência nos fornece para que possamos manobrar a realidade. A interpretação das expressões dêiticas, por exemplo, depende disso. Os 'grounds' podem aparecer em cascata, como nas expressões que contêm verbos dicendi. Em resumo, o 'ground', como enquadramento mental básico para se entender a comunicação humana, é, ele mesmo, uma compressão de redes mentais vastas e complicadas.

No capítulo 5 (Forbidden Ideas), Turner comenta alguns dos resultados mais complexos da integração conceitual avançada, casos em que duas histórias diferentes e complexas, e fortemente conflitantes entre si, em termos de sua estrutura básica, são integradas de modo a dar margem à criação de ideias novas e poderosas. Esses casos mostram como a integração conceitual avançada permite juntar histórias aparentemente incompatíveis. A habilidade de construir histórias é uma das ferramentas centrais da cognição humana. É assim que tentamos entender o ambiente em que vivemos. O exemplo de abertura de Turner é o da serpente do Paraíso, uma serpente que fala e tem intenções malévolas. Trata-se, pois, de um agente mal-intencionado que faz coisas e interage com outros. É a integração conceitual avançada que nos permite fazer isso: imaginar agentes com intenções e ações, cada um deles imaginando intenções, crenças e planos com relação aos outros. Imaginar histórias desse tipo é próprio da espécie humana. Nas palavras de Turner, o fruto proibido é a integração de duas histórias em conflito. A questão que se coloca é: como é que duas histórias incompatíveis não se suprimem mutuamente na mente humana? E a resposta é: através da integração conceitual avançada. A integração conceitual avançada (i) mapeia elementos de duas histórias diferentes, (ii) projeta de maneira seletiva alguns dos elementos das histórias numa nova história integrada e (iii) cria ideias novas, numa estrutura emergente nova. Outra ideia desenvolvida aqui se refere à recursão inerente às integrações conceituais, i. e., o resultado de uma integração conceitual pode servir de input a uma nova integração conceitual. Em resumo, a história do 'fruto proibido' é a história do ser humano moderno. Assim sendo, de acordo com Turner, 
chegou a hora de a ciência se preocupar com o descobrimento dos princípios que gerenciam a integração conceitual avançada, com os mecanismos que a tornam possível, com o modo como ele se desenvolve nas crianças e com a sua instalação na espécie humana. Sem dúvida, um projeto ousado.

No capítulo 6 (Artful Ideas) Turner nos mostra alguns dos padrões comuns e poderosos inerentes ao como integramos imagens visuais, especialmente aquelas ligadas à arte e ao cinema. Na verdade esse capítulo não traz nenhuma novidade importante, tratando-se apenas de uma extensão das ideias contidas nos capítulos anteriores, principalmente no capítulo 5. O que Turner desenvolve nesse capítulo é uma combinação da relação de representação com a relação de analogia, o que não chega a ser algo exatamente novo (cf. a noção de mapeamento de estrutura, de Getner, 1983; a noção de indução de esquema, de Gick e Holyoak, 1983, e a noção de integração de frames, de Hofstadter e Gabora, 1989). O que o autor acentua é a transferência analógica básica, que permeia o pensamento humano.

No capítulo 7 (Vast Ideas), Turner contempla a seguinte questão: como é que as pessoas, presas biologicamente ao aqui e agora, são capazes de produzir ideias amplas e novas, ideias essas capazes de recobrir grandes porções de tempo, espaço, ação e causalidade que ultrapassam o aqui e agora? Ao considerar essa pergunta, Turner coloca em discussão as noções de 'consciência estendida', de Damásio, a noção de 'consciência autonoética', de Tulving, e os comentários sobre o 'self', de Neisser. Turner procura responder a uma série de objeções que podem ser colocadas à pergunta inicial que, afinal de contas, configura-se como um dos maiores problemas para as ciências da mente. Ao final da discussão, Turner apresenta sua resposta, a mesma que varre todo o livro: é a nossa capacidade para fazer integração conceitual avançada que nos possibilita tudo isso. Somente o ser humano é capaz de pensar e sentir além dos limites das medidas impostas à sua espécie. Ou seja, se o ser humano é limitado por uma escala humana, a integração conceitual avançada permite que ele crie redes mentais amplas em escala humana e, portanto manobráveis, o que permite encapsular todo o universo, ou o tempo e o espaço, em escala humana e lidar com essa vastidão. A integração conceitual avançada faz parte de sua natureza. É próprio do ser humano ter ideias amplas e lidar com elas sem nenhum estranhamento.

No capítulo 8 (Tight Ideas), Turner completa o ciclo aberto no capítulo 7. A questão agora é a seguinte: como é que criamos, através da integração conceitual avançada, ideias portáveis, em escala humana? Turner inicia sua 
discussão aqui com a exposição de dois fatos óbvios: (i) nosso modo de pensar está ligado ao modo como nosso corpo funciona, ou seja, pensar com o propósito de gerenciar o corpo já é algo automatizado em escala humana; (ii) para pensarmos além dos limites impostos pelo nosso corpo, precisamos criar integrações conceituais que se utilizem de algum padrão que já conhecemos a partir de nossos próprios corpos. O primeiro padrão corpóreo comentado é o da simetria. Por exemplo, nosso cérebro é capaz de mapear nosso lado direito para o esquerdo e vice-versa (simetria bilateral). Outros padrões comentados e exemplificados ao longo do capítulo são evento-ação e personificação causal abstrata. Mas a discussão mais ampla do capítulo envolve a interação entre a integração conceitual avançada e a memória de trabalho. Os comentários de Turner conduzem à seguinte afirmação: a integração conceitual avançada amplia a memória, tornando-a mais poderosa, na medida em que ela, a memória, não precisará reter toda a extensão da rede mental, podendo se ocupar apenas da compressão que se aplica a toda essa rede. Em resumo, uma rede mental difusa se torna organizada e manobrável na sua compressão. Nos exemplos fornecidos por Turner podemos ver como essas compressões/ integrações conceituais se valem de padrões derivados de padrões corpóreos. Ao acrescentar à discussão a memória de longo prazo Turner salienta que quanto mais poderosa ela for, mais ela pode contribuir com material conceitual de input para uma integração conceitual. Assim sendo, a integração conceitual, a memória de trabalho e a memória de longo prazo estão imbricadas. A integração conceitual e a memória se complementam no pensamento humano. Ao final do capítulo, Turner nomeia alguns dos tipos mais comuns de redes de integração conceitual, tais como: hiper, simples, espelho, mudança, interação imaginada, ciclo, escopo simples, avançado (ou vórtice, ou escopo duplo), evento-ação, entre outros, cada qual com seu padrão próprio. O que fica claro, ao final, é que a integração conceitual segue princípios e obedece a restrições, criando uma grande variedade de redes integradas, proporcionando-nos ideias novas e amplas.

No capítulo 9 (Recurring Ideas), Turner comenta um tipo especial de rede mental integrada - a rede cíclica -, que é aquela na qual o que é criado na integração conceitual se repete. O primeiro exemplo ao qual Turner recorre para seus comentários, talvez o mais evidente, se refere à nossa maneira de conceber o tempo. Uma vez que a concepção de uma sequência real de dias não é algo mentalmente portável, nossa concepção de tempo cronológico não é mais que uma compressão. Em última instância falamos e pensamos em termos 
de padrões ou tipos gerais, e não em termos de casos específicos. No caso em questão, podemos ter dias, anos, estações do ano, décadas ou séculos cíclicos. Esses dias, anos ou estações do ano, na verdade, não se repetem, exceto dentro da compressão. As datas de aniversário fornecem um exemplo igualmente interessante: nascemos num dia específico, de um mês específico em um ano específico. Mas isso é projetado dentro do ano cíclico e, assim, podemos festejar nosso nascimento a cada ano. Eventos particulares e pontuais, como o aniversário e o Natal, têm raízes culturais, e é assim que organizamos nossas vidas. Turner amplia a ideia da rede cíclica para outros domínios e comenta outros casos de padrões que se repetem, como o pé métrico (no ciclo poético), o ritmo, as bases dos diferentes sistemas de contabilização, entre outros. Sendo assim, pode-se dizer que os seres humanos controlam melhor sequências infinitas quando os termos dessa sequência podem ser encapsulados num ciclo, na forma mais curta possível. É assim que nossa mente funciona. No entanto Turner aponta, também, que essa 'facilidade' só é verdadeira quando o ciclo é periódico. Se houver algum tipo de mudança na estrutura interna do ciclo, as dificuldades irão aparecer. Turner se pergunta, então: no caso das redes mentais amplas, que tipos de integração conceitual são mais adaptados à maneira como nós pensamos?

No capítulo 10 (Future Ideas), o último, Turner especula sobre possíveis projetos futuros e faz alguns comentários sobre aquilo que não foi tratado no livro. $\mathrm{O}$ autor nos diz que a investigação da origem das ideias coloca tipos diferentes de perguntas. A primeira delas é: O que a mente faz? Quais são os processos mentais acionados? O livro se organizou de forma a responder a essa pergunta, examinando processos mentais que nos garantem a possibilidade de criar ideias novas. Respondendo, nossa mente faz o que faz pela possibilidade de fazer integração conceitual avançada. A segunda pergunta é: Por que os seres humanos são como são? O que nos levou a sermos assim? Essa é uma pergunta difícil de ser respondida, relacionada à evolução da nossa espécie. Afinal, não sabemos quais foram as causas que nos conduziram ao nosso estado atual. Embora Turner não se aprofunde nessa questão, é importante notar que outros pesquisadores se ocuparam dela, como Gabora (2003), que examina as hipóteses disponíveis para se explicar aquilo que ela chama de revolução do Paleolítico Superior. A terceira pergunta é: Como os processos biológicos relativos ao cérebro e a outros sistemas sustentam a mente? Essa terceira pergunta também não tem resposta fácil, uma vez que a neurociência ainda não avançou muito no tratamento do pensamento de ordem superior. Por 
exemplo, não há nenhuma técnica de imagem cerebral que consiga detectar a integração conceitual. Contudo, embora as questões sobre o Por quê? e o Como? não sejam fáceis de responder, ainda assim Turner tece uma série de comentários interessantes sobre ambas, sugerindo possíveis caminhos e expectativas futuras. Embora as sugestões apresentadas tenham todas elas um caráter especulativo, vale a pena considerá-las.

O livro termina com um Apêndice (The Academic Workbench), no qual Turner retoma a gênese da hipótese da integração conceitual avançada, referindo-se principalmente a seu trabalho e ao trabalho conjunto com Fauconnier e, além disso, comenta uma série de outros trabalhos que evoluíram a partir dessa hipótese, envolvendo tópicos de natureza gramatical e uma abordagem experimental. Ao final, o autor afirma, muito modestamente, que a integração conceitual avançada resolve o problema central da linguagem, que pode ser resumido assim: como é que, com apenas um número limitado de pares de forma e sentido, podemos falar sobre uma infinidade de situações significativas? Para Turner, a integração conceitual avançada permite a compressão de espaços mentais diferentes e, nesse processo, projeta formas linguísticas oriundas de cada um desses espaços de input nessa compressão para expressar novos significados. Assim, um número limitado de pares de forma e sentido pode ser usado para expressar significados novos e ilimitados.

A questão a que precisamos responder agora é: vale a pena ler o livro? Embora a obra não apresente, a rigor, nenhuma novidade teórica, deixando ainda algumas lacunas que poderiam alimentar alguns pontos de discussão teóricos, conforme apontei para os capítulos seis (6) e dez (10), e embora os exemplos sejam excessivos e, talvez, pudessem ser reduzidos à metade (mas parece-me que essa é uma característica dos textos de Turner), ainda assim, recomendo fortemente a leitura do livro, por sua abrangência, pelo modo extremamente agradável como as ideias são apresentadas, pela minúcia com que o blending de escopo duplo é tratado e pelas perspectivas que ele abre para trabalhos e pesquisas futuros. Esse é um livro que precisa ser lido e estudado, mormente pelos interessados na área da linguística cognitiva. 
Referências

FAUCONNIER, Gilles. Mental spaces: Aspects of meaning construction in natural language. Cambridge, MA: MIT Press, 1985.

FAUCONNIER, Gilles. Mappings in thought and language. Cambridge, UK: Cambridge University Press, 1997.

FAUCONNIER, Gilles; TURNER, Mark. Conceptual integration networks. Cognitive science, v. 22, n. 2, p. 133-187, 1998.

FAUCONNIER, Gilles; TURNER, Mark. The way we think: Conceptual blending and the mind's hidden complexity. New York: Basic Books, 2002.

GABORA, Liane. Contextual focus: A cognitive explanation for the cultural transition of the Middle/Upper Paleolithic. In: ANNUAL MEETING OF THE COGNITIVE SCIENCE SOCIETY, 25., 2003, Boston. Proceedings... Hillsdale, NJ: Lawrence Erlbaum, 2003.

GENTNER, Dedre. Structure-mapping: A theoretical framework for analogy. Cognitive science, v. 7, p. 155-170, 1983.

GICK, Mary L.; HOLYOAK, Keith J. Schema induction and analogy transfer. Cognitive Psychology, v. 15, p. 1-38, 1983.

HOFSTADTER, Douglas; GABORA, Liane. Synopsis of a workshop on humor and cognition. Humor, v. 2, n. 4, p. 417-440, 1989.

LAKOFF, George; JOHNSON, Mark. Metaphors we live by. Chicago, IL.: University of Chicago Press, 1980.

LAKOFF, George; TURNER, Mark. More than cool reason: A field guide to poetic metaphor. Chicago, IL: University of Chicago Press, 1989.

TURNER, Mark; FAUCONNIER, Gilles. Conceptual integration and formal expression. Metaphor and symbolic activity, v. 10, p. 183-204, 1995.

TURNER, Mark. The literary mind: The origins of language and thought. New York: Oxford University Press, 1996. 